\title{
Collagenase-2- (MMP-8) as a Poimt - of- care Biomerker in Periodontal Disease in Patients with or Without Fixed Prosthesis Therapeutic Response to Doxycycline
}

\author{
ANDRA AUNGURENCEI ${ }^{1}$, IONUT LUCHIAN2*, ANCUTA GORIUC ${ }^{3 *}$, DANA CONSTANTINESCU4, IOANA MARTU ${ }^{1}$, \\ DIANA DIACONU POPA ${ }^{1}$, ANCA VITALARIU ${ }^{1}$, DIANA LUCHIAN ${ }^{5}$, KAMEL EARAR ${ }^{6}$, MONICA TATARCIUC ${ }^{1}$ \\ IUniversity of Medicine and Pharmacy Grigore T. Popa lasi, Faculty of Medical Dentistry, Departartment of Prosthetic Dentistry, \\ 16 Universitatii Str., 700115, Iasi, Romania \\ 2University of Medicine and Pharmacy Grigore T. Popa Iasi, Faculty of Medical Dentistry, Departartment of Periodontology, 16 \\ Universitatii Str., 700115, lasi, Romania \\ ${ }^{3}$ University of Medicine and Pharmacy Grigore T. Popa lasi, Faculty of Medicine, Departartment of Biochemistry, 16 Universitatii \\ Str., 700115, Iasi, Romania \\ University of Medicine and Pharmacy Grigore T. Popa lasi, Faculty of Medicine, Departartment of Immunology, 16 Universitatii \\ Str., 700115, lasi, Romania \\ ${ }^{5}$ University of Medicine and Pharmacy Grigore T. Popa Iasi, Faculty of Medicine, Departartment of Internal Medicine,16 \\ Universitatii Str., 700115, lasi, Romania \\ ${ }^{6}$ Dunarea de J os Uuniversity of Galati, Faculty of Medicine and Pharmacy, Department of Dental Medicine, 47 Domneasca Str., \\ 800008, Galati, Romania
}

\begin{abstract}
Periodontal diseases ranges from simple gum inflammation to serious disease that consists in major damage to the soft tissue and bone teeth support. Periodontal diseases affects the marginal and apical periodontium and results from the interaction between bacterial biofilm and the host response. To determine the concentrations of MMP-8, as a disease marker, in saliva in prosthetic and nonprosthetic, aggressive (AP) and chronic (CP) periodontitis, doxycycline treated patients. 40 patients were distributed into 3 groups: 12 diagnosed with aggressive $(A g P)$, 18 with chronic $(C P)$ periodontitis. Each of these groups was subdivided into 2 subgroups with and without fixed prosthesis. 10 patients were in the normal group. Matrix metalloproteinase 8(MMP-8) was evaluated before and after systemic doxycycline (Dox) treatment. mean MMP-8 value into the control group was $0.57 \mathrm{ng} / \mathrm{mL}$ with a standard deviation (STD) of 0,094 $\mathrm{ng} / \mathrm{mL}$. Highest MMP-8 value was established for the nonprosthesis AgP subgroup, before Dox treatment. The highest reduction in MMP-8 levels (40.8\%) was between nonprosthesis AgP before Dox treatment and the same group after Doxycycline treamtent. MMP-8 saliva levels are lower than GCF levels, mostly through a dilution mechanism as previous studies had shown. Our study revealed that saliva MMP-8 level is relible marker for AgP but not for CP. Doxycycline treatment, in terms of lowering MMP-8 levels is most effective in patients that have $A P$ and are also wearing fixed
\end{abstract}

Keywords: periodontal disease, fixed prosthesis, biomarker, doxycycline treatment

It has been established that periodontal disease results from the imbalance between oral microbiota with its antigens (necesary but not sufficient condition) on one side and the pateint's mainly neutrophil and macrophage involved nonspecific inflamatory reaction (NIR) on the other [1-4].

NIR leads to alterations of the tooth supporting structures, most important alveolar bone and periodontal ligament, the major damage being represented by the lost of the type I colagen in the periodontium with matrix metalloproteinase (MMPs) mediated, osteoclastic, phagocytic and plasminogen dependending destructive patways being well recognised [5-9].

The tests that are used in periodontal diagnosis, laborious and time consuming, are: probing depth (PD), clinical atachement level (CAL), bleeding on probing, plaque index and radiographic recordings and tend to express the consequences of the disease not the current status of the periodontium, these tests cannot predict the future destruction of the $\mathrm{P}$ or the response to treatment. [10-13].

Neutrophil mainly but also other major human cell types (fibroblasts, keratinocytes, macrophages and endothelial cells) released MMPs, are a family of zinc dependent metalloproteinases, the only class of enzymes in mammalians that can degrade colagens, MMP-8 and MMP9 having the mostcollagen cleavaging potency and a steep corelation between periodontal disease and their concentrations in the gingival crevicular fluid (GCF) and doxicyclin or tetracycline at subantimicrobial doses as a pharmacological ribosomal 30S unit level inhibitor and also being considered useful indicators for the severity of NIR $[14,15]$.

In the domain of periodontal diagnostics, oral fluid-based biomarkers have been studied mainly in the gingival crevicular fluid (GCF) and saliva $[6,7,16,17]$.

Gingival crevicular fluid (GCF) is a variant of serum transudate secreted by the gum in small amounts in healthy tissue and large quantity in periodontal disease that contains components of connective tissues, epithelial cells, bacteria, cytokines, enzymes, used for periodontal disease diagnostic and its treatment monitoring [18].

Saliva provides an easily available, noninvasive diagnostic tool for a rapidly widening range of diseases and clinical situations. Saliva, as a mirror of oral and systemic health, is a valuable source for clinically relevant information because it contains biomarkers specific for

*email: ionut_luchian@yahoo.com; ancuta.goriuc@yahoo.com

In this paper, all authors have an equal contribution as the first author. 
the unique physiologic aspects of periodontal diseases $[3,6,7]$.

The mainstay for periodontitis treatment is represented by the mechanical debridement followed by local or systemic use of antibiotics, doxycycline (Dox) at just 20 $\mathrm{mg}$ twice daily dose inducing a significant reduction in neutrophil colagenase GCF concentrations, with the local administration route being the best way in terms of gastrointestinal side effects, microbial antibiotic resistance, patient cooperation and other medication interaction [19].

Dental prosthesis (dental bridge) remains one of the most important treatment procedure with well recognised benefits in periondontal disease thrugh the mechanism of improving the teeth mobility [20-24].

Our study focused on saliva MMP8 levels surveyed in patients with aggresive (AP) and chronic periodontitis (CP) before and after Dox treatment.

\section{Experimental part}

\section{Matherial and method}

The study was conduced in Grigore.T.Popa University, the Periodontology Clinic. Patients saliva samples were procesed in to the Saint Spiridon Hospital Laboratory. The study included patients that adressed the Periodontology Clinic in the 2018-2019 period.

Three main groups were established. The first group included 12 patients with aggressive periodontitis (AgP) diagnosed according to clinical criteria: pocket depths over 4-5 $\mathrm{mm}$, gingival bleeding on probing and radiological signs that proved osteolysis. In this group, 2 subgroups were established one of eight patients with fixed prosthesis, the second one of 4, without fp. Specific AgP exclusion criterias were: chronic periodontitis (CP) present and previous 6 months antiinflamatory treatment.

The second group included 18 patients with CP diagnosed according to clinical criteria: pocket depths over $6 \mathrm{~mm}$, gingival inflamation, radiological proven horisontal osteolysis. In this group, 2 subgroups were established one for 10 patients with fixed prosthesis and another one for 8 patients without. Specific group inclusion criteria: age over 35 , more than 20 teeth present, no severe parodontitis episode present. Specific group exclusion criteria: presence of severe periodontitis.

Third group included 10 patients with normal clinical peridontal status.

General inclusion criteria for the patients were: the signing of informed consent, chronic (CP) or AgP present according to criteria.

General exclusion criteria were: smoking habit present, other chronic disease present, antibiotic treatment 3 months prior to the study, pregnancy, periodontal treatment 6 months prior to the study, allergies.

Fixed prosthesis patients were allready wearing their $\mathrm{fp}$ when entering the study, no fp was aplied as treatment during the study.

The study's purpouse was to determine and compare MMP-8 saliva concentrations in groups and subgroups of patients before and after Dox treatment.

MMP-8 levels, for each patient, were evaluated using Elabscience provided ELISA testing kit before and after Dox treament.

Saliva was sampeled from all patients in Eppendorf tubes, centrifuged for 2 minutes at $1000 \mathrm{rpm}$, with the resulting supernatant being between $400 \mu$ land $2000 \mu$ l. ELISA was performed using the supernatant to determine the concentration of MMP-8. Reactives used were adjusted to room temperature before use. Standard solution was achieved by adding $1 \mathrm{~mL}$ of reference standard sample diluent on the human liophilised standard MMP8 left for 10 minutes incubation time at room temperature. Eight standards were prepared at halfed concentrations starting from $10 \mathrm{ng} / \mathrm{mL}$, seventh dilution at $0,16 \mathrm{ng} / \mathrm{mL}$ and the eight being blank. In each ELISA plate well 100 microL from standard and probes were added. ELISA plate was than sealed and incubated at $37 \mathrm{C}$ for 90 minutes. 100 microL from biotinilated solution 0.01 dilution was added in each cell followed again by sealing and incubation for 60 minutes at 37 degrees. Bufer solution was than used for plate washing, 3 times at 1 minute interval. $100 \mathrm{~mL}$ of enzime Hrp (horseradish peroxidaze conjugate) in each ELISA plate well, followed by incubation at 37 degrees celsius for 30 minutes. Aspiration of each ELISA plate well with buffer solution, 5 times at 1 minutes interval. 90 microL of substrate solution was than added in each ELISA plate well and than incubated for 15 miunutes at 37 degrees celsius. Coloration was observed. Color instensity dictated the necesity of increasing or decreasing the incubation time up till 30 minutes. 50 microL of Stopping solution was than added in each ELISA plate well. Absorbance was than read at $450 \mathrm{~nm}$ using a ELISA plate reader ELISA BIO-RAD and Magellan software was used for analysis.

After saliva prelevation, all patients had conventional periodontal therapy consisting in removal of dental plaque and calculus, followed by smothing and planing of exposed surface of the roots in teeth with deep periodontal pokets.

Doxycicline was administered oraly in subantibacterial concentrations of $20 \mathrm{mg}$ twice daily for 7 days. No adverse effects were aknowledeged following antibiotic treatment.

Reevaluation of patient after Doxycycline included all examinations that were made at the begining of the study: periodontal status evaluation clinic and paraclinic. Saliva was resampeled and same assay protocol used for MMP-8 evaluation.

\section{Results and discussions}

All patients enroled completed the study. Patients were distributed into 3 main groups: AgP, CP and normal (control group). Each of the first two groups were split into with and without fp. All 4 subgroups thus obtained were further analysed before and after administration of Dox. Doxycycline was not administered to the control group.

Average, standard deviation and significance tests were performed on groups and subgroups. Intrasubgroup variation was analysed between values of MMP-8 before and after Dox administration. Mean value of MMP - 8 in control group was $0.257 \mathrm{ng} / \mathrm{mL}$ with standard deviation of $0.094 \mathrm{ng} / \mathrm{mL}$ and is the group that by far had the best concentration of values arround the average.

Highest average MMP-8 value has been aknowledged in the AgP without fixed prosthesis subgroup and before Dox treatment (mean value: $14.562 \mathrm{ng} / \mathrm{mL}$, SD: $2.851 \mathrm{ng} /$ $\mathrm{mL}$ ) followed by the values, in the same subgroup after Dox treatment (mean value: $9.320 \mathrm{ng} / \mathrm{mL}, \mathrm{SD}: 1.708 \mathrm{ng} /$ $\mathrm{mL}$ ). Lowest average MMP-8, was in the fixed prothesis CP subgroup after Dox treatment (mean value: $1.681 \mathrm{ng} /$ $\mathrm{mL}$, std: $0.904 \mathrm{ng} / \mathrm{mL}$ ).

The highest MMP-8 level variation was in the fixed prosthesis AP subgroup, before and after Dox treatment with a drop of $40.8 \%$ from the initial MMP-8 level. The lowest variation betw een before and after Doxycycline treatment was in the non prothesis CP subgroup (a 14.1\% drop in MMP-8 levels) (see Table 1). There was also significant MMP-8 level diference in the CP group between prosthetic and without prosthesis patients (mean value: $1.986 \mathrm{ng} /$ $\mathrm{mL}$ and $5.938 \mathrm{ng} / \mathrm{mL}$ respectevly).

Because the MMP-8 assay was conducted on saliva instead of GCF the values (expresed in $\mathrm{ng} / \mathrm{mL}$ ) were lower 


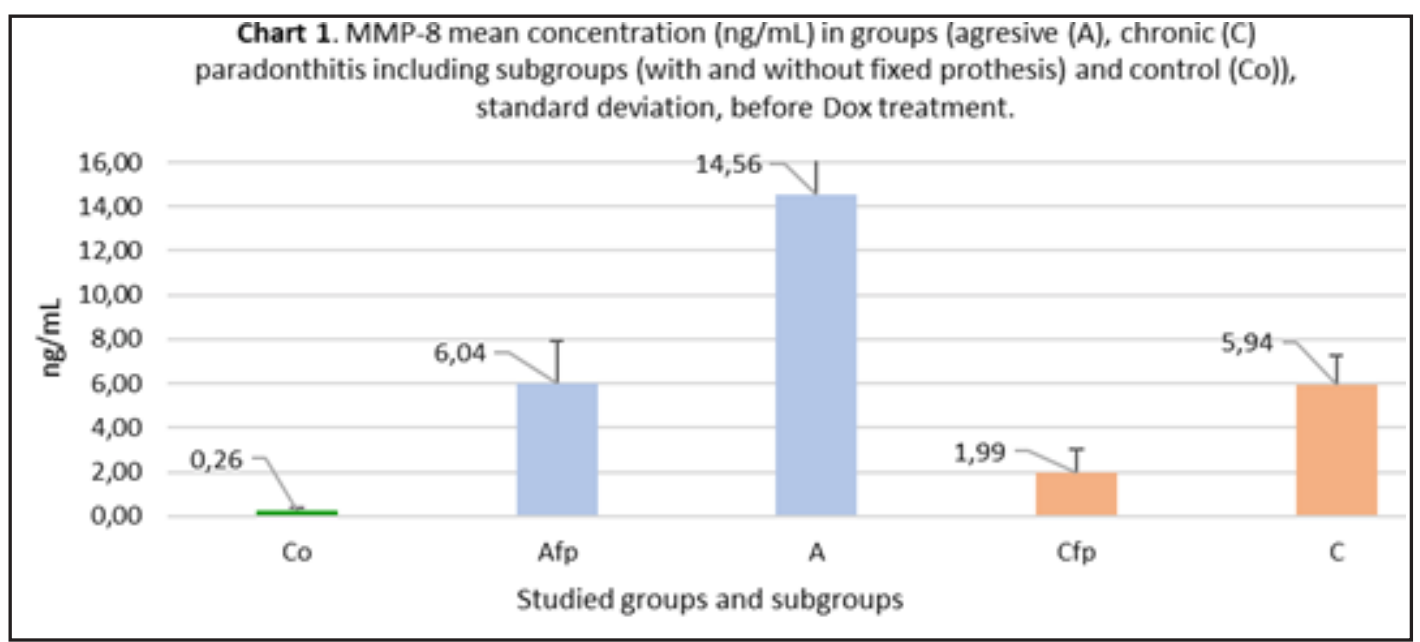

Co-control group; Afp-aggressive periodontitis (AgP) with fixed prothesis (fp) before doxycyclin treatment (Dox); A-AgP without fp before Dox; Cfp-chronic periodontitis (CP) with fp before Dox

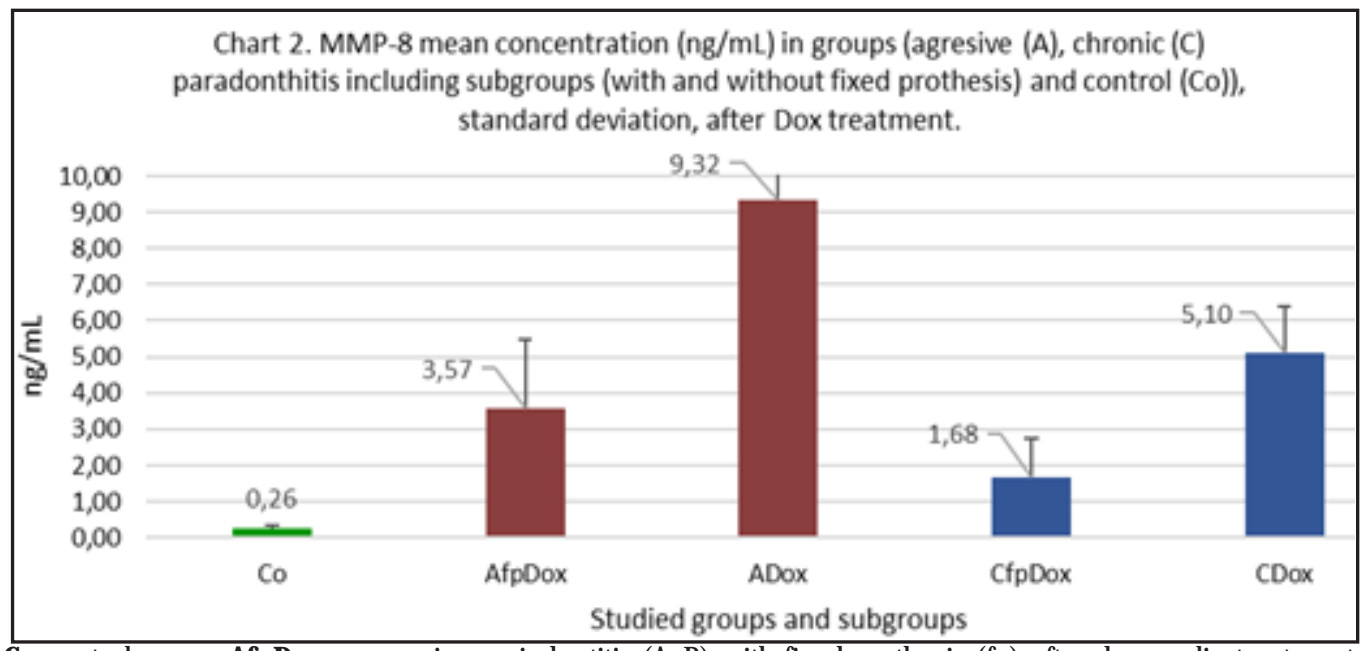

Co-control group; AfpDox- aggressive periodontitis (AgP) with fixed prothesis (fp) after doxycyclin treatment (Dox); ADox-AgP without fp after Dox; CfpDox-chronic periodontitis (CP) with fp after Dox; CDox-CP without fp after Dox.

\begin{tabular}{|c|c|c|c|}
\hline Groups and subgroups & $\begin{array}{l}\text { Average } \\
(\mathrm{ng} / \mathrm{mL})\end{array}$ & $\begin{array}{l}\text { Standard Deviation } \\
(\mathrm{ng} / \mathrm{mL})\end{array}$ & $\begin{array}{l}\text { In Group MMP-8 level } \\
\text { variation (the drop in value } \\
\text { between before and after D } \\
\text { treatment) in } \%\end{array}$ \\
\hline $\mathbf{C}$ & 0,257 & 0.09 & \\
\hline Afp & 6,039 & 1,919 & \multirow{2}{*}{40,8} \\
\hline AfpDox & $3,570^{-}$ & 1,162 & \\
\hline $\mathrm{A}$ & 14,562 & 2,851 & \multirow{2}{*}{35,9} \\
\hline ADox & $9,320^{-\cdots}$ & 1,708 & \\
\hline Cfp & 1,986 & 1,067 & \multirow{2}{*}{15,3} \\
\hline CfpDox & 1,681 & $0,904^{-}$ & \\
\hline $\mathrm{C}$ & 5,938 & 1,297 & \multirow{2}{*}{14,16} \\
\hline CDox & 5,097 & 1,113 & \\
\hline \multicolumn{4}{|c|}{$\begin{array}{l}\text { C-control group; Afp- aggressive periodontitis (AgP) with fixed prosthesis (fp) before doxycycline } \\
\text { treatment (Dox); AfpDox-AP with fp after Dox; A-AP without fp before Dox; ADx-AgP without } \\
\text { fixed prosthesis after Dox; Cfp-chronic periodontitis (CP) with fp before Dox; CfpDox-CP with fp } \\
\text { after Dox; C-CP without fp before Dox; CDx-CP without fp after Dox. }\end{array}$} \\
\hline
\end{tabular}

Tabel 1

MMP-8 LEVELSIN GROUPS (AGGRESSIVE-AP, CHRONIC PERIODONTITIS-CP AND CONTROL-C), SUBGROPUS (WITH FIXED AND WITHOUT FIXED PROTHESIS), BEFORE AND AFTER DOXYCYCLINE TREATMENT AND IN GROUP VARIATION BEFORE AND AFTER DOX TREATMENT than the average values in GCF in other published findings through a dilution mechanism most likley [25-27].

When statistical analysis was made for AgP fp subgroup, a statistical significant difference was established between before and after Doxycycline treatment average MMP-8 values ( $6.04 \mathrm{ng} / \mathrm{dL}$ and $3.57 \mathrm{ng} / \mathrm{dL}$ respectivley) and control group, $p<0.001$.

The same statistical analysis was made for AgP non fp subgroup, significant difference was established between before and after Dox treatment average MMP-8 values (14.56ng/dL and 6.039 $\mathrm{ng} / \mathrm{dL}$ respectivly) and control group, $p<0.001$.

Statistical analysis on CP fixed prothesis subgroup did not establish significant diference between before and after Dox treatment average MMP-8 values $(1,98 \mathrm{ng} / \mathrm{dL}$ and 1.68 $\mathrm{ng} / \mathrm{dL}$ respectivley) $(\mathrm{p}=0.38)$; same analysis made in CP non fixed prothesis subgroup also did not establish significant diference between before and after Doxycycline 


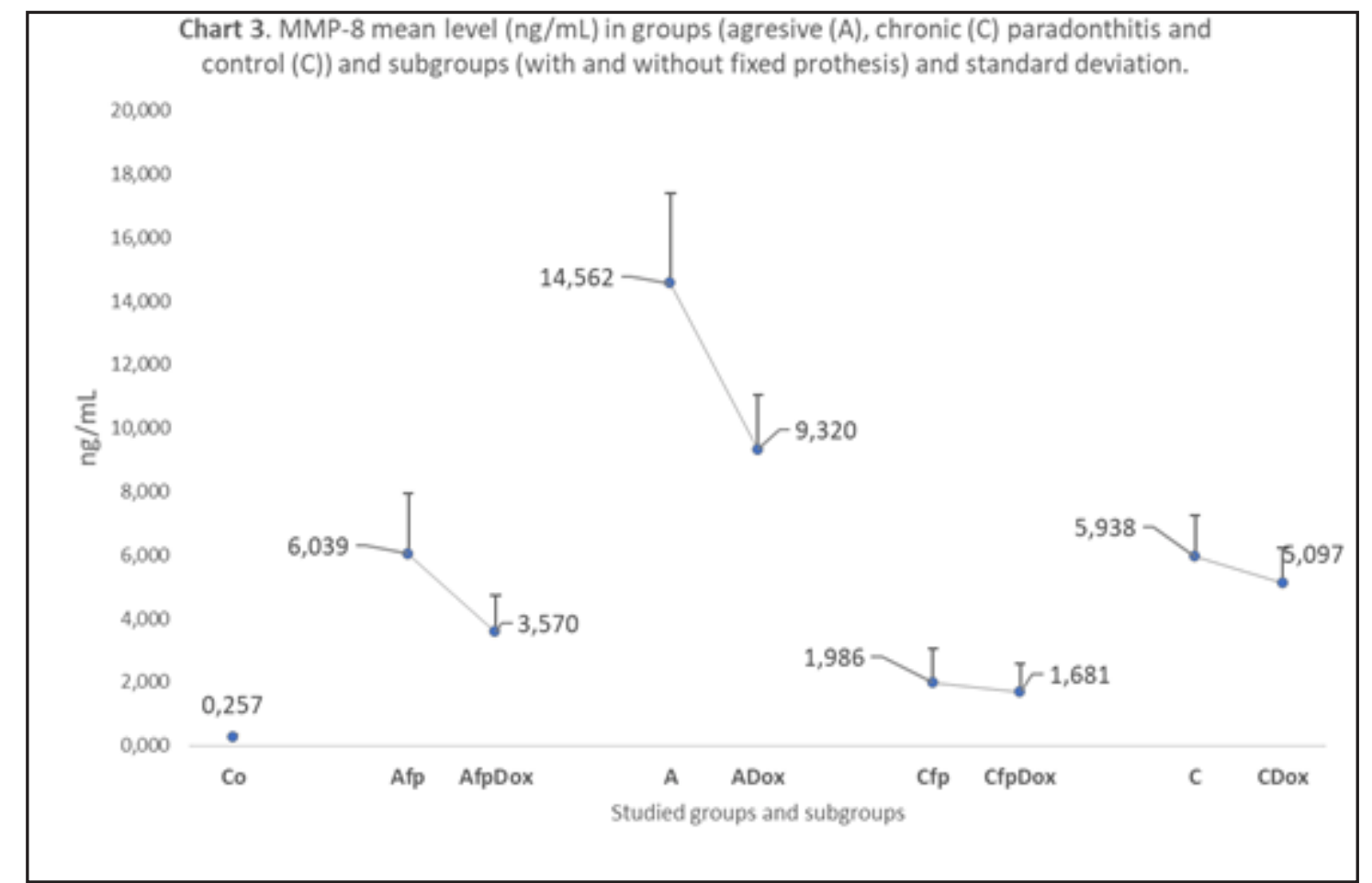

C-control group; Afp-acute periodontitis (AgP) with fixed prothesis (fp) before doxycyclin treatment (Dox); AfpDox$A P$ with $f p$ after Dox; A-AP without fp before Dox; ADx-AgP without fp after Dox; Cfp-chronic periodontitis (CP) with $f p$ before Dox; CfpDox-CP with fp after Dox; C-CP without fp before Dox; CDx-CP without fp after Dox.

treatment average MMP-8 values ( $5.94 \mathrm{ng} / \mathrm{dL}$ and $5.09 \mathrm{ng} /$ $\mathrm{dL}$ respectively) $(p=0.25)$. This may be because $C P$ as a hole has different lesions dominant trigerring pathways than MMP-8 mediated.

When statistical analysis was performed between fixed prothesis and non fixed prothesis patients it has been established that wearing fp significantly decreased mean MMP-8 values $(p<0.001)$ both in AgP and CP groups before and after Dox treatment.

From the point of view of the doxycycline administration impact, only in AgP group Dox treatment significantly lowered the mean MMP-8 levels $(p<0.001)$ while in $C P$ group it didn't. Doxycycline treatment should be asociated with fixed prothesis treatment for maximum therapeutic effect.

Regarding hostmodulation therapies Doxycycline is one many posibilities, acting on one component of the inflammation cascade, on matrix metallooproteinases, howevwer, another class of immunomodulatory drugs are DMARDS, which influence the release and action of certain biomolecules and cytokines such as IL 1, IL-6 II 17, TNF alfa [28].

However, the detection of salivary MMP-8 can be considered a biomarker of periodontitis and could be used as a valuable indicator of health and pathologic process in patients with and without fixed prosthesis.

\section{Conclusions}

Salivary MMP-8 represents a reliable marker for $\mathrm{AgP}$ but not so reliable for CP. Doxycycline treatmentadministration is most effective in patients that have AgP and are also wearing fixed prothesis (dental bridges) and it is well proven through MMP-8 levels.

\section{References}

1.GENCO, R.J., Host responses in periodontal diseases: Current concepts. J Periodontol 1992;63(4 Suppl):338-55.
2.LUCHIAN, I., MARTU, I., MARTU, C., GORIUC, A., BELDIMAN, A.,MARTU, S. Rev. Chim. (Bucharest), 67, no. 6, 2016, p. 1073-1075. 3.NITESCU-KAPPENBERG, D.C., MIHAI, C., OANTA, C., MARTU, I., VOLOVAT, S.R., MARTU, S. Rev. Chim. (Bucharest), 68, no. 3, 2017, p. 549-552.

4.GEORGESCU, M., VRINCEANU, D., RADULESCU, L., TUSALIU, M., MARTU, C., CURUTIU, C., HUSSIEN, M.D., BUDU., V. et al. Rom Biotechnological Letters, 22, no. 4, 2017, p. 12681-12686.

5.PAGE, RC; J Periodontal Res 1991; 26(3 Pt 2):230-42.

6.SUFARU, I.G., SOLOMON, S.M., PASARIN, L., MARTU-STEFANACHE, M.A., OANTA, A.C., MARTU, I., CIOCAN PENDEFUNDA, A., MARTU, S. Rom J of Oral Rehab, 8, no.4, 2016, p. 42-46.

7.URSARESCU, I.G., PAVAL, D., SOLOMON, S.M., PASARIN, L., BOATCA, M., NICOLAICIUC, O., NITESCU, D.C., MARTU, S. Rom J of Oral Rehab, 8, no. 1, 2016, p. 97-103.

8.MURARIU, A., FORNA, D.A., MANOLACHE, F., FORNA, N.C. Rom. J of Oral Rehab. 9, no. 3, 2017, p. 48-54.

9.SOLOMON, S.M., IOVAN, G., PASARIN, L., SUFARU, I.G., MARTU, I., LUCHIAN, I., MARTU, M.A., MARTU, S. Rom. J. Oral Rehab, 9, no.3, 2017, p. 89-96.

10.LUCHIAN, I., NANU, S., MARTU, I., TEODORESCU, C., PASARIN L, SOLOMON S, MARTU, MA, TATARCIUC, M, MARTU S, Rom. J of Oral Rehab, 10, no. 2, 2018, p. 63-69.

11.POPA, C.G., LUCHIAN, I., IOANID, N., GORIUC, A., MARTU, I., BOSINCEANU, D., MARTU, M.A., TIRCA, T., MARTU, S. Rev. Chim. (Bucharest). 69, no. 6, 2018, p. 1578-1580.

12.LUCHIAN, I., POPA, C., ZAHARESCU, A., MARTU, I., SUFARU, I.G., MARTU, M.A., SIOUSTIS, I., IOVAN, A., MARTU, S. Rom. J. of Oral Rehab. 11, no. 2, 2019, p. $274-278$

13.CIOCAN-PENDEFUNDA, A., URSARESCU-SUFARU, IG, MARTUSTEFANACHE, M.A. , IOANID, N., MARTU, I., PENDEFUNDA, V., IFTENE, G. Rom. J. of Oral Rehab. 8, no. 4, 2016, p. 57-61.

14. BIRKEDAL-HANSEN, H.J Periodontol 1993;64(5 Suppl):474-84.

15.NEDZI-GOORA, M; GORSKA, R., KOSTRZEWA-JANICKA, J., KOWALSKI, J. Centr Eur J Immunol 2017; 42(4):342-346.

16.NICOLAE, V., CHISCOP, I., CIORANU IBRIC, V.S., MARTU, M.A., LUCHIAN, A.I., MARTU, S., SOLOMON, S.M., Rev Chim. (Bucharest), 66, no. 12,2015, p. 2121-2123 
17.SOLOMON, S., URSARESCU, I., MARTU, A., LUCHIAN, I., AGOPFORNA, D., MARTU, S., FORNA, N.C. Rev. Chim.(Bucharest). 66, no. 8, 2015, p. 1166-1168.

18.KINNEY, JS., MORELLI, T., OH, M., et al. J Clin Periodontol. 2014, 41(2):113-120.

19.FARAMARZI, M., MARAMI, Z., SHIRMOHMMADI, A., CHITSAZI, M., RAHBAR, M., SADIGHI, M., J. of Int. Oral Health 2016; 8(7):781-786.

20.TATARCIUC, M., VITALARIU, A., LUCA, O., AUNGURENCEI, 0., FRATILA, D., DIACONU-POPA, D. Rev. Chim. (Bucharest), 69, no.2, 2018, p. 407-410.

21.DIACONU-POPA, D.,, VITALARIU, A., HOLBAN-CIOLOCA, C., AUNGURENCEI, A., LUCA, O., TATARCIUC, M.. Rev Chim (Bucharest) 68, no. 10, 2017, p. 2382-2385

22.DIACONU, D., TATARCIUC, M.S., MELINTE, A., VIPALARIU, A.M., Rom. J. of Oral Rehab. 5, no.3, 2013, p. 84-90.
23.BOSINCEANU, D.G., SANDU, I.G., BOSINCEANU, D.N., MARTU, I., SURLARI Z., FORNA, N.C. Mat. Plast., 55, no. 3, 2018, p. 423-425 24.MARTU, I., LUCHIAN, I., DIACONU-POPA, D., BOSANCEANU, D.G., VITALARIU, A., LUCA, O., TATARCIUC, M. Rom. J. of Oral Rehab., 9, no. 1,2017, p. 27-31.

25.SURLIN, P., OPREA, B., SOLOMON, S.M. et al. ROMANIAN JOURNAL OF MORPHOLOGY AND EMBRYOLOGY Rom. J. of Morphology and Embryology, 55, no.3, supll.S, 2014, p.1137-1141.

26.SURLIN, P., RAUTEN, A.M., MATEESCU, G.O. et al. Rom. J. of Morphology and Embryology, 50, no. 2, 2009, p. 181-184

27.SURLIN, P., RAUTEN, A.M., MOGOANTA, L., et al. Rom. J. of Morphology and Embryology, 51, no. 3, 2010, p. 515-519.

28.MARTU, M.A., REZUS, E., POPA, C., SOLOMON, S.M., LUCHIAN, I., CIOCAN PENDEFUNDA, A., SIOUSTIS, I., ANTON, D., MARTU, S., FOIA, L. Rom. J. of Oral Rehab. 10, no. 4, 2018, p. 161-165

$\overline{\text { Manuscript received: } 6.11 .2019}$ 